\title{
LOS ANIMALES EN EL ORDENAMIENTO JURÍDICO ESPAÑOL Y LA NECESIDAD DE UNA REFORMA ${ }^{1}$
}

\author{
Inmaculada Vivas Tesón \\ Profesora Titular de Derecho civil \\ Universidad de Sevilla \\ E-mail: ivivas@us.es
}

\begin{abstract}
RESUMEN: En el presente trabajo se aborda el estudio del estatuto jurídico del animal en el Derecho español, partiéndose de su consideración como seres sensibles, sobre todo, a partir del artículo 13 del Tratado de Funcionamiento de la Unión Europea, con el que se produjo un verdadero cambio de paradigma en cuanto a la relación humano-animal que, a diferencia de otros países de nuestra misma familia jurídica, aún no ha logrado plasmarse en nuestro Código civil. El Derecho Administrativo y el Penal se han ocupado de la protección y bienestar del animal, aunque no de forma plenamente satisfactoria.
\end{abstract}

Palabras clave: animal; ser sensible; reforma legislativa

\begin{abstract}
The aim of the of present paper is to study the legal status of the animal in Spanish Law, based on the assumption that they are sentient beings, especially, from Article 13 of the Treaty on the Functioning of the European Union, with which a real paradigm shift in terms of the humananimal relationship that, unlike other countries in our same legal family, has not yet managed to translate into our Civil Code. Administrative and Criminal Law have been concerned with the protection and welfare of the animal, although not in a fully satisfactory manner.
\end{abstract}

Keywords: animal; sentient being; legislative reform

SUMARIO: I. LOS ANIMALES Y SU CONSIDERACIÓN COMO «SENTIENT BEINGS». 1.1. El abandono del paradigma antropocéntrico. 1.2. Primeros pasos a nivel internacional. 1.3. La posición de la Unión Europea y el art. 13 del TFUE como pieza clave. 1.4. Una mirada al Derecho extranjero. II. LOS ANIMALES EN EL ORDENAMIENTO JURídiCo ESPÃ̃oL. 2.1. El necesario reconocimiento constitucional de la protección y el bienestar animal. 2.2. El anacrónico Código civil. 2.3. La jungla administrativa. 2.4. La insatisfactoria tutela penal. III. BIBLIOGRAFía.

1 El presente trabajo se se incluye entre los resultados del proyecto de investigación "Discapacidad, Enfermedad Crónica y Accesibilidad a los Derechos" (DER2016-80138-R) del Ministerio de Economía y Competitividad, así como del Grupo de Investigación PAIDI SEJ617 "Nuevas dinámicas del Derecho privado Español y Comparado". 


\section{LOS ANIMALES Y SU CONSIDERACIÓN COMO «SENTIENT BEINGS»}

\subsection{El abandono del paradigma antropocéntrico}

En el último cuarto del siglo pasado se inicia un movimiento global y multidisciplinar de etólogos, antropólogos, biólogos, neurocientíficos, filósofos, intelectuales y algún que otro jurista que promueve un giro mental hacia los animales: sufren, son sensibles y, por ello, no puede seguir manteniéndose el tradicional y rancio paradigma antropocéntrico del enfermizo narcisismo del autodesignado Homo sapiens. No, no son cosas².

En dicho proceso descosificador de los animales se comienza a considerarlos compañeros de camino con los cuales instaurar una relación horizontal y ya no meros objetos de dominio ${ }^{3}$. Se produce, así, un viraje en el estatus jurídico del animal. Inicialmente, las normas se preocupan por su bienestar ${ }^{4}$, limitándose prácticamente a proscribir el maltrato

2 En la Antigüedad, Aristóteles era defensor del antropocentrismo, mientras que Pitágoras Séneca, Plutarco, Porfirio o Plotino representaban la ética contraria pues en sus reflexiones acerca de la relación de los humanos con los animales consideraban que el maltrato a éstos era una muestra de crueldad por parte de aquéllos. De las dos escuelas, fue la aristotélica la que tuvo, sin duda, mayor influencia en el pensamiento occidental.

Durante la Edad Media, a finales del siglo XII y principios del XIII, figura clave fue San Francisco de Asís, quien protegía a los animales por ser obra de Dios, razón por la cual los consideraba "hermanos" de los hombres.

Sin embargo, no sería hasta el siglo XVIII cuando algunos autores publicaran sus inquietudes filosóficas acerca de la defensa de los animales, destacando, entre ellos, el anglosajón Jeremy BENTHAM, uno de los fundadores del utilitarismo moderno y a quien se considera el pionero en plantear los derechos de los animales en su obra Introduction to the principles of morals and legislation, printed by T. Payne and son, London, 1789 (una versión en abierto puede consultarse en https://oll.libertyfund.org/titles/bentham-the-works-of-jeremy-bentham-vol-1/ simple\#lf0872-01_head_028), en la que afirma: "It may come one day to be recognized, that the number of the legs, the villosity of the skin, or the termination of theos sacrum, are reasons equally insufficient for abandoning a sensitive being to the same fate. What else is it that should trace the insuperable line? Is it the faculty of reason, or, perhaps, the faculty of discourse? But a full-grown horse or dog is beyond comparison a more rational, as well as a more conversable animal, than an infant of a day, or a week, or even a month, old. But suppose the case were otherwise, what would it avail? the question is not, Can they reason? nor, Can they talk? but, Can they suffer?". Ya en el siglo XX destaca el filósofo australiano SINGER, P.: Animal liberation: a new ethics for our treatment of animals, HarperCollins, Random House, New York, 1975, obra en la que defiende la capacidad de sentir dolor que, al igual que el hombre, tienen los animales, de modo que la consideración moral no debe limitarse a la especie humana, en concreto, el principio de igualdad moral debe extenderse a todos los seres, negros o blancos, masculinos o femeninos, humanos o no humanos; y también el norteamericano REGAN, T.: The case for animal rights, University of California Press, Los Ángeles, 1983, quien hace hincapié en la necesidad de una teoría de los derechos de los animales basándose no sólo en la sintiencia sino también en la condición de todos los seres sintientes de constituirse como sujetos de una vida que tiene un valor inherente. Años más tarde, el jurista norteamericano FRANCIONE, G. L.: Animals, property and the Law, Temple University Press, Philadelphia, 1995, sugiere suprimir la consideración de los animales como cosas sobre las que se tiene propiedad; por su parte NUSSBAUM, M.: "Beyond 'Compassion and Humanity': Justice for Non-Human Animals", en Animal rights: current debates and new directions, SUNSTEIN y NUSSBAUM (eds.), University Press, Oxford, 2004, propone considerarlos sujetos de justicia política que han de ser reconocidos en el campo jurídico.

Indudablemente, las investigaciones de Jane Goodall, Dian Fossey y Birutè Galdikas, quienes trabajaron bajo el auspicio del antropólogo keniano Louis Leakey (de ahí que se las conozca como "los Ángeles de Leakey") en el estudio de la etología de los primates (chimpancés, gorilas y orangutanes respectivamente) fueron cruciales para comprender la evolución humana y la necesidad de proteger los derechos de los animales.

3 Recuérdese que la dominación del animal por el hombre ya es consagrada en la Biblia, concretamente, en Génesis 1:24-28 9:2-3.

4 La creación del término "bienestar animal" se debe al Reino Unido y a su "Animal Welfare" y las conocidas "Five Freedoms" o "Five Welfare Needs" (freedom from hunger and thirst; freedom from discomfort; freedom from pain, injury and disease; freedom to express normal behaviour; y freedom from fear and distress), país donde, según unánimemente se afirma, tiene origen el movimiento de defensa animal. 
animal y regular sus condiciones higiénico-sanitarias. Con el tiempo, dicha protección se irá ampliando ${ }^{5}$ sobre la base de considerarlo un individuo en sí mismo, un ser sensible al igual que nosotros, lo que ha sido científicamente demostrado ${ }^{6}$.

Desde esta perspectiva, se plantea el debate (aún abierto y útil o no júzguelo el lector) en torno a si los animales tienen o no derechos, si éstos pueden extenderse también a los sujetos no humanos ${ }^{7}$. En definitiva y con permiso de RODOTÀ, si los animales tienen "il diritto di avere diritti"".

Sean o no titulares de derechos, es más que evidente que los animales son seres sensibles dignos de protección 9 . Si no es seguro que los seres vivos no humanos tengan derechos, sí lo es que a los humanos nos corresponden deberes hacia ellos.

\subsection{Primeros pasos a nivel internacional}

La mirada jurídica hacia la animalidad comienza a cambiar con la Declaración universal de los derechos del animal de 23 de septiembre de 1977, adoptada por la Liga internacional de los derechos del animal y proclamada al año siguiente (y aprobada por la UNESCO y la ONU), que si bien se trataba de una mera declaración de intenciones completamente desprovista de valor normativo, supuso un importante hito en cuanto a una toma de posición respecto a la relación del hombre hacia los animales ${ }^{10}$. Destacamos su art. 1: "Todos los animales nacen iguales ante la vida y tienen los mismos derechos a la existencia".

Sin embargo, el marco jurídico para los cuarenta y siete países del Consejo de Europa lo constituye el Convenio europeo sobre protección de animales de compañía, hecho en Estrasburgo el 13 de noviembre de 1987 y ratificado por España ni más ni menos que

5 Como señala PEREZ MONGUIÓ, J. M. a: "Marco jurídico de la protección animal en España desde 1929 hasta 2015: el lento y firme trote del mastín", en Revista Aranzadi de Derecho Ambiental, 2015, núm. 32, pp. 285-333 (BIB 2015 \17053), "los cambios en la concepción de los animales han generado normas de protección que ya no se circunscriben a evitar el maltrato físico o a imponer la obligación de mantenerlos en buenas condiciones higiénico-sanitarias, sino que tienen un objetivo más amplio en el que subyace una visión integral y completa de los animales en general y del animal como individuo, en particular".

6 En 2012, trece eminentes neurocientíficos firmaron la Cambridge Declaration on Consciousness (la cual puede consultarse en http://fcmconference.org/img/CambridgeDeclarationOnConsciousness.pdf), en la que concluyeron que los animales no humanos tienen conciencia: "the weight of evidence indicates that humans are not unique in possessing the neurological substrates that generate consciousness. Nonhuman animals, including all mammals and birds, and many other creatures, including octopuses, also possess these neurological substrates".

7 Sobre la materia, vid. CAVALIERI, P.: The animal question: Why non-human animals deserve human rights, Oxford University Press, New York, 2001; MAZZONI, C. M.: "La questione dei diritti degli animali", en Belfagor, 2012, vol. 67, pp. 265-276, quien en p. 265 se plantea las siguientes preguntas: "Gli animali devono avere diritti? Gli animali sono titolari di diritti? Di quali diritti si parla? Si tratta di diritti innati? Ovvero, qua lè l'autorità o il potere che attribuisce loro diritti? Tutti gli animali sono, o debbono essere, titolari di diritti; oppure solamente alcuni di essi; e chi stabilisce quali specie sono ammesse e quali no; c'è una graduatoria?"; VADALÀ, V.: "Prospettazione storico-evolutiva dei diritti degli animali", en Giustizia civile, 2017, núm. 3, pp. 549-577; y REY PÉREZ, J. L.: Los derechos de los animales en serio, Dykinson, Madrid, 2018.

8 Con ello hacemos alusión a la obra de RODOTÀ, S.: Il diritto di avere diritti, Milano, Il saggiatore, 2013.

9 Para PÉREZ MONGUIÓ, J. M. a: Animales de compañía. Régimen jurídico en el Derecho administrativo, Bosch, Barcelona, 2005, p. 95, "el hecho de que los animales no deban ser considerados como personas, ni sean titulares de derechos no quiere decir, en modo alguno, que no deban ser protegidos, pues éste es un deber de primer orden".

10 PÉREZ MONGUIÓ, J. M.a': Animales de compañia. Régimen jurídico en el Derecho administrativo, cit., pp. 5051, considera la Declaración un documento de gran importancia porque es el primer texto internacional que de forma expresa y contundente declara que todos los animales poseen derechos y, además, recoge por primera vez los parámetros que deben servir de guía para otras normas destinadas a la protección de animales. 
tres décadas después, en 2017 (con entrada en vigor el 1 de febrero de 2018) ) $^{11}$, el cual reconoce que el hombre tiene la obligación moral de respetar a todas las criaturas vivas, teniendo presentes las especiales relaciones existentes entre el hombre y los animales de compañía, los cuales tienen importancia "por su contribución a la calidad de vida y su consiguiente valor para la sociedad".

Destaca también la Declaración A/66/750, de 20 de marzo de 2012 de la ONU, que reconoce el bienestar animal como merecedor de su consideración a través del desarrollo sostenible. Conforme a ello, en The Sustainable Development Goals 2030 Agenda (SDGs) da gran relevancia a la protección animal.

Sin embargo, creemos que la ONU debería dar un paso más, esencial en estos momentos, hacia una Convención internacional sobre la protección del bienestar animal por la cual se sentaran unas bases y objetivos comunes sobre el respeto de los animales como seres que sienten y sufren. Tras la enorme repercusión mundial de la Convención de Nueva York sobre los derechos de las personas con discapacidad de 2006, que tanto nos sacudió a todos y nos puso frente a una realidad hasta entonces invisible, lo que proponemos no sólo no nos parece descabellado sino que es absolutamente necesario. A nuestro juicio, no bastaría una Declaración ${ }^{12}$, sino un instrumento vinculante y directamente aplicable, como lo es la Convención neoyorkina, que impulse decisivamente la actividad legislativa de los distintos países. Es, a nuestro juicio, la única forma de lograr, de manera efectiva, una concienciación global acerca de la protección y bienestar animal.

\subsection{La posición de la Unión Europea y el art. 13 del TFUE como pieza clave}

A nivel de la Unión Europea ${ }^{13}$, además de numerosas Directivas y Reglamentos sobre protección de animales en distintos ámbitos (utilización para fines científicos, ensayos para la producción de cosméticos, protección en el momento de su sacrificio, etc. $)^{14}$, el primer paso en la nueva concepción de los animales como seres sensibles lo constituye, a nuestro parecer, la Resolución del Parlamento Europeo de 6 de junio de 1996, iniciativa materializada en el Protocolo 33 sobre la Protección y Bienestar de los Animales, anexo al Tratado Constitutivo de la Comunidad Europea, en su versión de 1997 dada por el Tratado de Ámsterdam, en vigor desde el 1 de mayo de 1999.

Sin embargo, la superación de la categoría animal-cosa y el reconocimiento de la sintiencia animal tenía escaso valor jurídico al recogerse en un Protocolo, no siendo hasta el 1 de diciembre de 2009 cuando alcance carácter vinculante como principio general y

11 BOE núm. 245, de 11 de octubre.

12 Es preciso señalar que la World Society for the Protection of Animals (WSPA) propuso hace años la "Declaración Universal de Bienestar animal" (DUBA), la cual ha encontrado el respaldo de numerosos países pero aún no ha sido aprobada por la ONU.

13 Un gran número de ciudadanos de la UE expresan su apoyo al bienestar animal y desean que se mejore al respecto, como refleja el Eurobarómetro de 2016 (que puede consultarse en http://ec.europa.eu/commfrontoffice/ publicopinion/index.cfm/ResultDoc/download/DocumentKy/71348.

Más recientemente, en el último informe de consulta a los ciudadanos de la Unión europea sobre las prioridades futuras de la Unión de abril de 2019 (https://ec.europa.eu/commission/sites/beta-political/files/online-consultationreport-april-2019_en.pdf), los consultados dan más importancia al bienestar animal que a la lucha contra la corrupción.

14 El vasto corpus normativo europeo relativo a los animales se encuentra recogido en http://www.bienestaranimal. eu/baeu.html. 
constitucional de Derecho originario de la UE al incorporarse al art. 13 del Tratado de Funcionamiento de aquélla (tras las modificaciones operadas por el del Lisboa de 13 de diciembre de 2007), el cual tiene el siguiente tenor literal:

"al formular y aplicar las políticas de la Unión en materia de agricultura, pesca, transporte, mercado interior, investigación y desarrollo tecnológico y espacio, la Unión y los Estados miembros tendrán plenamente en cuenta las exigencias en materia de bienestar de los animales como seres sensibles, respetando al mismo tiempo las disposiciones legales o administrativas y las costumbres de los Estados miembros relativas, en particular, a ritos religiosos, tradiciones culturales y patrimonio regional"15.

Desde el punto de vista técnico, lo que más llama la atención es que se opte por la categoría de "seres sensibles"16, la cual irrumpe como un tertium genus que hace quebrar la clásica dicotomía jurídica sujeto/objeto en la que se apoyan nuestras normas conforme a las cuales todo lo que no es persona es cosa.

Dicho esto, es sabido que los Tratados constitutivos son las normas supremas del ordenamiento jurídico comunitario y condicionan la interpretación y la validez de las demás disposiciones de la UE y del Derecho nacional vinculado a ella. Por ello, el art. 13 del TFUE se ha convertido en pieza clave del avance de las legislaciones proteccionistas de los Estados de la Unión ${ }^{17}$. En nuestra opinión, el mandato europeo contiene un principio transversal e introduce un "favor animalis" en la labor hermenéutica de la normas de los Estados miembros y, por consiguiente, también de las nuestras.

Digno de mención es, por ello, el Estatuto de Autonomía de la Comunidad autónoma de Canarias, la reciente Ley Orgánica 1/2018, de 5 de noviembre, que en su art. 35 recoge lo siguiente: "en los términos que se fijen por ley, de acuerdo con la Constitución y el Tratado de Funcionamiento de la Unión Europea, las Administraciones públicas canarias velarán por el mantenimiento y la salvaguarda de los animales, además de reconocerlos como seres que sienten y con derecho a no ser utilizados en actividades que conlleven maltrato o crueldad. Asimismo, se fijará el régimen de infracciones y sanciones". Como puede comprobarse, la Carta Magna canaria reconoce la sintiencia animal y el deber de velar por su protección sustentándose para ello, de manera expresa, en la norma fundamental española y europea.

15 Para un estudio más amplio, vid. LOPEZ DE LA OSA ESCRIBANO, P.: El Derecho del bienestar animal en Europa y Estados Unidos, Aranzadi, Cizur menor (Navarra), 2012 y BARZANTI, F.: "La tutela del benessere degli animali nel Trattato di Lisbona", en Il Diritto dell'Unione Europea, 2013, pp. 49-71.

16 El citado precepto, en su versión en inglés, utiliza la expresión "sentient beings", la cual es traducida por los distintos países como "seres sintientes", "seres sensibles" o "seres vivos dotados de sensibilidad".

En España tal vez los términos "seres sintientes" y "sintiencia" resulten raros pero, según la RAE y la Fundéu, ambos son voces bien formadas que se emplean para aludir a la capacidad de sentir de los seres vivos. El verbo "sentir" tiene una variación vocálica en la raíz por la que las formas con "e", como "sentimos", alternan con las formas con "i", como "sintió". Según el Diccionario panhispánico de dudas, ello ha favorecido la creación de la variante "sintiente", que convive con el adjetivo "sentiente", derivado del latín "sentiens, -entis". Este adjetivo, "sintiente", que la Academia considera válido, es la variante que más se emplea y de ella deriva el sustantivo "sintiencia", también adecuado.

17 En opinión de ROCA FERNÁNDEZ-CASTANYS, M. ${ }^{a}$ L.: El transporte intracomunitario de animales de compañia, Reus, Madrid, 2018, p. 11, la fuerza del art. 13 del Tratado de Lisboa es muy limitada en cuanto que con la última previsión, la necesidad de respetar las disposiciones legales o administrativas y las costumbres de los Estados miembros relativas, en particular, a ritos religiosos, tradiciones culturales y patrimonio regional, se introduce una excepción tan amplia que puede afirmarse que queda reducida a una mera declaración de intenciones desprovista de toda eficacia. 
Asimismo, el art. 13 del TFUE es expresamente traído a colación por la reciente Sentencia del Juzgado de Primera Instancia núm. 9 de Valladolid de 27 de mayo de 2019 para considerar a un perro cuya posesión se discutía tras una ruptura sentimental de sus titulares un sujeto dotado de especial sensibilidad.

\subsection{Una mirada al Derecho extranjero}

Si echamos la mirada más allá de nuestras fronteras encontramos países que han empezado a recoger este nuevo sentir social hacia los animales y el deber de brindarles protección en sus normas, algunos, incluso, en sus textos constitucionales: en 2002 Alemania $^{18}$, un par de años después Austria ${ }^{19}$ y Suiza ${ }^{20}$ y en 2007 Luxemburgo $^{21}$.

En cuanto a los países europeos (unos Estados miembros y otros Schengen), encontramos los que, a nivel infra constitucional, reconocen legislativamente la categoría animal-no cosa pero sin determinar cuál es exactamente la verdadera naturaleza de los animales. Entre ellos, por orden cronológico y ciñéndonos a los Códigos civiles, citamos: Austria ( $\$ 285 \mathrm{a}$ del ABGB de 1 de julio de 1988²2), Alemania ( $\$ 90 \mathrm{a}$ del BGB de 20 de agosto de 199023), Suiza (art. 641a del ZGZ de 4 de octubre de 2002 ${ }^{24}$ ), Liechtenstein (art. 20a del Sachenrecht de 14 de mayo de $2003^{25}$ ) y República Checa ( $\$ 494$ CCC que entró en vigor el 1 de enero de $2014^{26}$ ).

18 Art. 20a. Para conocer al detalle los antecedentes de la reforma constitucional alemana, vid. LÓPEZ DE LA OSA ESCRIBANO, P.: "La protección jurídica de los animales en Alemania y Francia", en Revista Aranzadi de Derecho Ambiental, 2013, núm. 25, pp. 281-291 (BIB 2013\1782).

19 Art. 11.1.

20 Art. 80.

21 Art. 11 bis.

22 §285a del ABGB: "Tiere sind keine Sachen; sie werden durch besondere Gesetze geschützt. Die für Sachen geltenden Vorschriften sind auf Tiere nur insoweit anzuwenden, als keine abweichenden Regelungen bestehen". Con posterioridad y acorde con ello, se realizaron dos reformas en el ABGB: el §1332a en relación a la indemnización debida por costos derivados de un animal herido y el $\$ 250$ al declarar la inembargabilidad de los animales que no se destinen a la venta.

$23 \$ 90$. a del BGB: "Tiere sind keine Sachen. Sie werden durch besondere Gesetze geschützt. Auf sie sind die für Sachen geltenden Vorschriften entsprechend anzuwenden, soweit nicht etwas anderes bestimmt ist".

Como recoge LÓPEZ DE LA OSA ESCRIBANO, P.: "La protección jurídica de los animales en Alemania y Francia", cit. (BIB 2013\1782), "algunas voces de la doctrina alemana consideran que la modificación del artículo 90a ha supuesto una reforma de carácter social con la que justificar la aparente preocupación que el régimen jurídico alemán puede tener con los animales. En principio, consideran que todo permanece como antes, al tener en cuenta el contenido del apartado tercero del propio artículo. Por mucho que el legislador considere a los animales como cosas vivas, seguirán siendo aplicables a aquéllos las normas referentes a las cosas, por lo que la situación no ha mejorado especialmente. Por lo tanto, la consideración de los animales como cosas o como no cosas es controvertida".

Además de la modificación del §90.a del BGB, se procedió a modificar aspectos relacionados con la nueva consideración jurídica de los animales tales como en el ámbito de la indemnización (251, pfo. 2 BGB) y de los derechos y deberes de los propietarios (903, BGB) o en procedimiento de ejecución forzosa (765 ZPO) y de embargo (811c ZPO).

24 Art. 641a (nouveau): "I. Animaux

1 Les animaux ne sont pas des choses.

4 Sauf disposition contraire, les dispositions s'appliquant aux choses sont également valables pour les animaux".

25 Art. 20a del Sachenrecht: "Tiere

1) Tiere sind keine Sachen.

2) Soweit für Tiere keine besonderen Regelungen bestehen, gelten für sie die auf Sachen anwendbaren Vorschriften".

26 El §494 del Código Civil checo señala: "Living animals have special importance and value as living creatures endowed by senses. Living animals are not objects; provisions regarding objects are to be applied to animals only if this application does not contravene with the nature of the animal". Para un mayor estudio de la consideración de los animales en dicho ordenamiento, vid. MÜLLEROVÁ, H.: "Animals finally above objects and stricter 
Por su parte, Francia (art. 515-14 del Code Civil en su nueva redacción operada por el art. 2 de la Loi n. ${ }^{\circ}$ 20115-177 du 16 février 2015 relative à la modernisation et à la simplification du droit et des procédures dans les domaines de la justice et des affaires intérieures ${ }^{27}$ ) y Portugal (art. 201. ${ }^{\circ}-\mathrm{B}^{28}, \mathrm{C}^{29}$ y D $^{30}$ del Código civil, introducido por la Lei n. ${ }^{\circ}$ 8/2017, de 3 de março), a diferencia de los países antes citados, reconocen expresamente, mediante una fórmula positiva, que los animales son seres vivos sensibles, en clara sintonía con el art. 13 del TFUE. Si nos paramos a pensar, se incorpora una categorización que no altera sustancialmente la existente en el Código Civil entre bienes y personas, si bien se continúan aplicando a los animales las normas relativas a las cosas en defecto de previsiones específicas para aquéllos, razón por la cual puede considerarse que tales reformas son meramente teóricas. A efectos prácticos, suponen más un cambio social que jurídico, plano en el que todo sigue igual que antes: el mismo perro con distinto collar.

No obstante, se detecta un cambio puesto que en las primeras reformas de los Códigos civiles europeos se utilizó una formulación negativa en el sentido de que los animales no son cosas o bienes, en tanto que en las más recientes se ha preferido una positiva como seres sensibles o sintientes, lo que, sin duda, es más acorde con la directriz marcada por la UE.

Por lo que respecta al Codice civile de 1942, en él aún persiste la consideración del animal como bien mueble ex art. 812, si bien se ha puesto sobre la mesa la necesidad de su reforma, siendo mientras tanto los tribunales los que, a golpe de sentencia, están considerándolo un "essere senziente" 31 .

criminalization of cruelty: some insights in czech animal legislation”, en dA:Derecho Animal, 2012, vol. 3, núm. 1, pp. 1-7 (puede consultarse en https://revistes.uab.cat/da/article/view/v3-n1-mulerova/179).

27 Art. 515-14 del Code civil: "Les animaux sont des êtres vivants doués de sensibilité. Sous réserve des lois qui les protègent, les animaux sont soumis au régime des biens".

Es preciso indicar que el país galo ya reconoció como seres sensibles en 1976 en su Código Rural y de Pesca Marítima, en concreto, en su art. L214-1 (ley del 10 de julio de 1976) a los animales que tienen propietario. En 2015, la reforma del Code civil armoniza dicho texto con el Código penal y con el citado Código Rural, con lo que se dota de coherencia interna al ordenamiento jurídico francés.

Para un estudio más detenido, vid. LELANCHON, L.: "La reforma del estatuto jurídico civil de los animales en el Derecho francés", en dA: erecho Animal, 2018, vol. 9, núm. 3, pp. 72-79.

28 Art. 201. ${ }^{\circ}-\mathrm{B}$ : "Animais

Os animais são seres vivos dotados de sensibilidade e objeto de proteção jurídica em virtude da sua natureza".

29 Art. 201. ${ }^{\circ}-\mathrm{C}$ : "Proteção jurídica dos animais

A proteção jurídica dos animais opera por via das disposições do presente código e de legislação especial".

30 Art. 201. -D: "Regime subsidiário

Na ausência de lei especial, são aplicáveis subsidiariamente aos animais as disposições relativas às coisas, desde que não sejam incompatíveis com a sua natureza".

31 Así, citamos el caso del Tribunal de Milano, Sezione IX civile, en su Decreto de 134 de marzo de 2013, acerca de la tenencia de los gatos en un acuerdo de separación conyugal: "Nell'attuale ordinamento - anche in conseguenza dalla entrata in vigore della Legge 4 novembre 2010, n. 201, di ratifica ed esecuzione della Convenzione europea per la protezione degli animali da compagnia, fatta a Strasburgo il 13 novembre 1987 - il sentimento per gli animali ha protezione costituzionale e riconoscimento europeo cosicché deve essere riconosciuto un vero e proprio diritto soggettivo all'animale da compagnia (Trib. Varese, decreto 7 dicembre 2011). Quanto il Legislatore ha, di fatto, riconosciuto, in tempi recenti, con la legge 11 dicembre 2012, n. 220 posto che, modificando l'art. 1138 cod. civ., ha previsto che "le norme del regolamento [condominiale] non possono vietare di possedere o detenere animali domestici". Ne consegue che, una interpretazione evolutiva ed orientata delle norme vigenti, impone di ritenere che l'animale non possa essere più collocato nell'area semantica concettuale delle "cose", secondo l'impostazione tralaticia ma debba essere riconosciuto come "essere senziente" (v. Trattato di Lisbona che modifica il trattato sull'Unione europea e il trattato che istituisce la Comunità europea, firmato a Lisbona il 13 dicembre 2007). Non essendo l'animale una «cosa» (v., ad es., artt. 923 c.c.), bensì un essere senziente, è legittima facoltà dei coniugi quella 
Fuera del ámbito europeo reconocen normativamente a los animales como sujetos de derechos o seres sensibles: Nueva Zelanda [Title Paragraph (a)(i) Animal Welfare Act of 1999, en la redacción dada por la Animal Welfare Amendment Act, de 10 de mayo de 2015 32 , Canadá (art. 898.1 Code Civil du Quebec ${ }^{33}$, introducido por la Loi sur la protection sanitaire des animaux de 4 de diciembre de 2015) y Colombia (art. 655.2 del Código Civil $^{34}$, introducido por Ley 1774/2016, de 6 de enero). El Código civil de Moldavia (art. 287 , reformado en $2002^{35}$ ) opta, en cambio, por la fórmula animal-no cosa.

En algunos países de América Latina se reconoce desde hace tiempo que los animales son seres sensibles, pero en leyes protectoras y no en los códigos civiles con la sola excepción de Colombia, si bien en estos momentos se están promoviendo proyectos de reforma de dichos cuerpos legales para que los animales dejen de ser catalogados como cosas.

Es el caso de Chile, que reconoce expresamente que los animales son seres sensibles en su Ley núm. 20380 de 3 de octubre de 2009 sobre protección de animales ${ }^{36}$, pero ha sido en abril de este mismo año cuando se ha presentado el proyecto de ley sobre calificación jurídica de los animales con la intención de establecer en el Código civil una nueva categoría jurídica para los animales, declarándose como "seres vivos dotados de sensibilidad" y no como bienes muebles ${ }^{37}$.

di regolarne la permanenza presso l'una o l'altra abitazione e le modalità che ciascuno dei proprietari deve seguire per il mantenimento dello stesso".

En la misma línea se pronuncia también el Tribunal de Sciacca, Sezione Unica, que en su Decreto de 19 de febrero de 2019 considera que "il sentimento per gli animali costituisce un valore meritevole di tutela, anche in relazione al benessere dell'animale stesso".

También es cierto que algunas resoluciones judiciales mantienen la consideración de animal como cosa mueble, como la Sentencia de la Corte de Cassazione, Sezione II, de 25 de septiembre de 2018.

32 Puede consultarse en http://www.legislation.govt.nz/act/public/1999/0142/latest/whole. html?search=sw_096be8ed817c720c_sentient_25_se\&p=1.

33 Art. 898.1: "Les animaux ne sont pas des biens. Ils sont des êtres doués de sensibilité et ils ont des impératifs biologiques.

Outre les dispositions des lois particulières qui les protègent, les dispositions du présent code et de toute autre loi relative aux biens leur sont néanmoins aplicables".

34 Artículo 655. "Muebles

Muebles son las que pueden transportarse de un lugar a otro, sea moviéndose ellas a sí mismas como los animales (que por eso se llaman semovientes), sea que sólo se muevan por una fuerza externa, como las cosas inanimadas. Exceptúense las que siendo muebles por naturaleza se reputan inmuebles por su destino, según el artículo 658. Reconózcase la calidad de seres sintientes a los animales".

35 El art. 287 del C.c. moldavo dispone:

“(1) Animalele nu sînt lucruri. Ele sînt ocrotite prin legi speciale.

(2) În privinţa animalelor se aplică dispoziţiile referitoare la lucruri, cu excepţia cazurilor stabilite de lege.

(“1) Los animales no son cosas. Están protegidos por leyes especiales.

2) Con respecto a los animales se aplicarán las disposiciones que regulan las cosas, a excepción de los casos previstos por la ley").

36 Art. 2, pfo. 1 de la Ley núm. 20380: "Artículo 2.-El proceso educativo, en sus niveles básico y medio, deberá inculcar el sentido de respeto y protección a los animales, como seres vivientes y sensibles que forman parte de la naturaleza".

37 El proyecto de ley propone crear un art. 564 bis dentro del nuevo título "De los animales" del Libro II del Código Civil que contenga el siguiente texto: "Los animales son seres vivos dotados de sensibilidad y sujetos de protección legal de conformidad con las leyes especiales que rijan al efecto. Sólo en aquellos aspectos no regulados por leyes especiales y en la medida que no afecten su calidad de seres sensibles, regirán supletoriamente las normas de este título aplicable a los bienes muebles". 
También tienen aún pendiente reformar sus Códigos civiles Brasil ${ }^{38}$ y Argentina ${ }^{39}$, lo que no deja de ser bastante curioso. Y ello lo decimos porque Brasil cuenta con un referente judicial a nivel mundial, el de la chimpancé Suiza, primer caso en la Historia en el que se interpuso un habeas corpus para la protección de la vida e integridad de un sujeto no humano ${ }^{40}$, admitiéndose una relación procesal entre un no humano, Suiza, y un humano, el responsable del zoo de Bahía y el Director de Biodiversidad de la Secretaría de Medioambiente y Recursos hidráulicos. Por su parte, Argentina tiene otro leading case, el caso de la orangután Sandra ${ }^{41}$, en el que también se recurrió al mismo remedio del habeas corpus ${ }^{42}$.

A la vista de tales precedentes judiciales, podría pensarse que únicamente los homínidos no humanos son, por su proximidad genética a los humanos, sujetos de derechos, mientras que los restantes animales han de seguir siendo cosas. Sin embargo, ambos países están afrontando en estos momentos la reforma de sus respectivas legislaciones civiles para incorporar a ellas la descosificación de todos los animales no humanos sin excepción, pues no hay unas categorías que merezcan mayor tutela que otras.

38 En Brasil se presentó el Projeto de Lei do Senado núm. 351 de 2015, que propone añadir un párrafo al art. 82 (rubricado "Dos Bens Móveis") del Código civil del siguiente tenor: "Os animais não serão considerados coisas". A diferencia de nuestra Carta Magna, la Constitución federal prohíbe expresamente la crueldad sobre los animales en su art. $225 \S 1$, VII, precepto éste dedicado al medio ambiente.

Para un estudio más detenido, vid. CARDOZO DIAS, E.: A tutela jurídica dos animais, Belo Horizonte - Minas Gerais, 2018.

39 El 10 de mayo de 2018 se presentó el proyecto de Ley 26994 mediante la cual se pretende incorporar un art. 30 bis al reciente Código civil y comercial de la Nación que disponga: "Sujetos de derechos sintientes no humanos. Son sujetos de derechos sintientes no humanos todos los animales domésticos o domesticados".

40 En septiembre de 2005, a instancias de una ONG brasileña, se logró que un juez de Bahía aceptara un habeas corpus sobre una chimpancé llamada Suiza, recluida desde hacía diez años en una jaula estrecha y expuesta al público en el parque zoológico de dicha ciudad. La noche anterior al juicio y tras filtrarse que la decisión del juez sería favorable a conceder la libertad al homínido, Suiza apareció muerta a causa de un envenenamiento en pos de evitar que la sentencia sentara jurisprudencia. Pese al trágico final, Suiza se ha convertido post mortem y urbi et orbi en el símbolo de la defensa de los derechos de los animales.

El texto completo de la sentencia puede consultarse en la Revista Brasileira de Direito Animalhttps://portalseer. ufba.br/index.php/RBDA/article/view/10259.

41 En diciembre de 2014, la Sala 2. a de la Cámara Federal de Casación penal de la Ciudad Autónoma de Buenos Aires consideró que Sandra, encerrada en un zoológico bonaerense durante más de veinte años y en condiciones físicas y psíquicas poco adecuadas, era una "persona no humana", reconociéndole intereses legítimos propios y proveyendo a su protección y ello porque "a partir de una interpretación jurídica y no estática, menester es reconocerle al animal el carácter de sujeto de derechos, pues los sujetos no humanos son titulares de derechos, por lo que se impone su protección en el ámbito competencial correspondiente". Su nuevo hogar es el Center for Great Apes de Florida.

La sentencia puede consultarse en http:/www.saij.gob.ar/camara-federal-casacion-penal-federal-ciudadautonoma-buenos-aires-orangutana-sandra-recurso-cadacion-habeas-corpus-fa14261110-2014-12-18/123456789-011-1624-1ots-eupmocsollaf.

A dicho caso han seguido después otros. En noviembre de 2016 una jueza de Mendoza concedió el habeas corpus a otra chimpancé, Cecilia, afirmando en su sentencia que "resulta innegable que los grandes simios, entre los que se encuentra el chimpancé, son seres sintientes por ello son sujetos de derechos no humanos". Y añade: "no se trata aquí de otorgarles los derechos que poseen los seres humanos sino de aceptar y entender de una buena vez que estos entes son seres vivos sintientes, que son sujetos de derechos y que les asiste, entre otros, el derecho fundamental a nacer, a vivir, a crecer y morir en el medio que les es propio según su especie. No son los animales ni los grandes simios objeto de exposición como una obra de arte creada por el hombre".

42 Para un más amplio estudio acerca de dicho remedio, vid. CHIBLE VILLADANDOS, M.a J.: "La protección del animal no humano a través del habeas corpus", en Derecho y Humanidades, núm. 27, 2016, pp. 37-67. 


\section{LOS ANIMALES EN EL ORDENAMIENTO JURÍDICO ESPAÑOL}

\subsection{El necesario reconocimiento constitucional de la protección y el bienestar animal}

Muy ilustrativo en relación a la preocupación mundial por el bienestar animal y la deficiente respuesta del ordenamiento jurídico español al respecto parangonada con la de otros países europeos es el Auto del Juzgado de Instrucción núm. 1 de Lugo de 14 de noviembre de 2017, que en su FJ. $1 .^{\circ}$ afirma:

“desgraciadamente, la violencia en nuestra sociedad, es un fenómeno muy extendido y presenta diversas manifestaciones. Pero sin duda alguna, una de las más deplorables y despiadadas caras que es capaz de mostrar la violencia, y evidencia hasta dónde puede llegar la crueldad y la perversidad humana, es la que se ejerce contra los animales. Además, no resulta exagerado afirmar, que quien desprecia la vida hasta el punto de maltratar o abandonar a un animal, habitualmente, también despliega su instinto agresivo contra una mujer, los hijos, menores, ancianos, sus vecinos o contra otros ciudadanos a los que considera inferiores.

Paralelamente, es una realidad indiscutible el escaso interés que hasta el momento se ha demostrado en España por el bienestar animal, siendo uno de los países europeos que dispone de una de las legislaciones 'más relajadas' en materia de protección animal, aun reconociendo los pequeños logros conseguidos en la última década, por impulso, como también resulta habitual, de la normativa europea, y fundamentalmente, por la presión y lucha denodada, constante e inquebrantable de asociaciones animalistas y ecologistas; posición ésta, la de los poderes públicos, que contrasta con la cada vez mayor preocupación social sobre el bienestar animal, sentida no sólo por la evidente necesidad de impulsar una cultura basada en la no violencia, así como en el respeto y en no infligir dolor ni sufrimiento a ningún ser vivo, sino incluso, guiada por el interés más utilitario y egoísta derivado del beneficio que al ser humano, tanto en su perspectiva individual como social, le reporta el poder gozar de un medio ambiente y de un mundo animal saludable, viable, benéfico y sano. Partiendo de que los animales son seres sensibles y reconociendo su contribución a la calidad de vida humana, poco a poco, el bienestar animal se ha ido convirtiendo en una inquietud mundial, aunque en España, el panorama, todavía, resulta bastante desolador, si tenemos en cuenta que anualmente, miles de animales son maltratados y abandonados, en ocasiones sometidos a actos de extraordinaria crueldad, mutilaciones, sacrificios innecesarios, inanición o a condiciones higiénicas deleznables, o simplemente, son matados, torturados, extenuados o desechados por inservibles, por una incomprensible diversión en determinados 'espectáculos públicos' o 'deportivos".

Descendiendo al Derecho español, en el que nuestra Constitución de 1978 no hace la más mínima alusión a los animales, el citado Auto señala:

"en el marco español, a diferencia de lo que sucede en otros países de nuestro entorno, como el caso de Alemania, Suiza y Austria, cuyas Constituciones proclaman la protección de los animales, nuestra Norma Suprema, no incluye entre su articulado mención alguna al bienestar o a la protección de los animales, más allá de lo previsto en su artículo 45, donde se sanciona el derecho de disfrutar de un medio ambiente adecuado, que es donde genéricamente se ha venido a encajar, de forma ciertamente forzada, el derecho a la pro- 
tección de los animales, con las limitaciones derivadas de su propia redacción, ya que al margen de que solo se contempla un principio rector de política social y económica no exigible directamente ante los tribunales, limita su perspectiva a una visión antropocéntrica del individuo, que es el que tiene derecho a gozar y disfrutar del medio ambiente como forma de mejorar su calidad de vida, con omisión de la perspectiva de los animales, como seres vivos que son, individualizados y necesitados de tutela y protección".

Y, a continuación, plantea una propuesta de reforma constitucional:

"por ello es que, en esta convulsa época de la Historia, en la que con ardor se viene defendiendo una reforma constitucional, no esté de más aprovechar la oportunidad que se brinda para recordar que otros sectores ponen este ímpetu reformista en la imperiosa necesidad de dotar de rango constitucional a la protección de los animales como política pública y administrativa, para equipararnos así a otros países, miembros de la Unión Europea, acabando de paso con la dispersión y desigualdad normativa existente".

Partiendo de la convicción de que los animales requieren una protección constitucional (y, consiguientemente, un título competencial específico hoy día inexistente), creemos, en la línea del citado Auto, que el bienestar animal no tiene cabida en el derecho al disfrute de un medio ambiente adecuado reconocido por el art. $45 \mathrm{CE}^{43}$. La defensa de los animales y la del medio ambiente encierran valores e intereses propios no siempre coincidentes, por ello que nuestra Constitución deba brindarles tutela individual y separadamente.

Por otro lado, consideramos que la reforma que propone el Juzgado de Instrucción, si bien es necesaria, no urge, pues el bienestar animal ya encuentra un claro soporte constitucional, el art. 13 del TFUE, norma de Derecho originario de la UE y, por tanto, principio de máximo rango directamente aplicable en nuestro ordenamiento jurídico ex art. 93 de la $\mathrm{CE}^{44}$.

\subsection{El anacrónico Código civil}

Nuestro Código civil está profundamente impregnado de la visión cosificadora de los animales, objetos de la propiedad individual, eje central de todas las codificaciones (europeas y latinoamericanas) del sistema de civil law o Derecho continental ${ }^{45}$ que siguieron la estela del Code napoleónico, en palabras de GROSSI, “el último eslabón de la larga

43 Sostiene dicha postura DOMÉNECH PASCUAL, G.: Bienestar animal contra derechos fundamentales, Atelier, Barcelona, 2004, p. 136.

44 Más extensamente, ALONSO GARCÍA, E.: "El bienestar de los animales como seres sensibles-sentientes: su valor como principio general, de rango constitucional, en el Derecho español”, en Los principios jurídicos del Derecho administrativo, SANTAMARÍA PASTOR (dir.), La Ley, Madrid, 2010, pp. 1427-1510 (LA LEY 1120/2011).

$45 \mathrm{Al}$ respecto, señala CARTWRIGTH, J.: Introducción al Derecho inglés de los contratos, Aranzadi, Cizur menor (Navarra), 2019, p. 46, que un denominador común de muchos sistemas modernos de civil law es que su Derecho privado está basado en un conjunto sistemático de normas generales contenidas en textos legislativos -típicamente, un 'código'- como el francés, belga, alemán, italiano u holandés pero "la diferencia no reside sólo en la existencia de un código civil, ya que los países escandinavos son generalmente reconocidos como pertenecientes a la tradición de civil law aunque no cuentan con códigos completos y sistemáticos. (...) Un rasgo en verdad distintivo de common law frente a nuestros vecinos 'civilistas', es la limitada recepción en Derecho inglés de los principios del Derecho romano. El término civil law se emplea para describir a estos ordenamientos europeos debido a la recepción por parte de éstos del lenguaje, las ideas y estructuras propias del Derecho romano con el resurgimiento y redescubrimiento del Corpus Iuris Civilis de Justiniano que tuvo lugar en Italia a finales del Siglo XI y se extendió con distintos grados de influencia en los distintos países del continente". 
cadena de continuidad que arranca de la antigüedad clásica..., el más vivo testimonio del individualismo propietario" $"$.

La cosificación de los animales en el Código civil español se refleja en muchos de sus preceptos, entre otros, los arts. 334, 335, 346, 499, 526, 610, 612, 1491 a 1499 y 1579. También se hace mención a ellos en sus arts. 1800, 1905 y $1906^{47}$.

Son bienes muebles ${ }^{48}$ (y, en ciertos casos, inmuebles por destino o relación pertenencial ex art. 334.6. ${ }^{049}$ ), semovientes, apropiables (por tanto, alienables y embargables) y fructíferos.

El interés que el legislador civil muestra por el animal, al que en alguna ocasión se dirige con un lenguaje un tanto despectivo (como en el art. 499, en el que encontramos expresiones como "animales dañinos" o "despojos") y sin preocuparse mínimamente de su bienestar animal, procede exclusivamente de la proyección que sobre él ejerce la voluntad del propietario. El titular de la propiedad sobre el animal puede ejercer sobre él todas las facultades dominicales que le son legalmente reconocidas como usar y disfrutar del mismo, aprovecharse económicamente o disponer de él y de sus crías, reivindicar o, incluso, abandonarlo.

El desajuste entre la lógica propietaria de dicho Cuerpo legal de finales del siglo XIX y la creciente sensibilidad animalista de la sociedad española del siglo XXI es más que evidente.

Además de ello, no se contemplan algunos supuestos de hecho, ciertamente inimaginables a finales del siglo XIX pero reales en la época actual y que, por consiguiente, a día de hoy, adolecen de orfandad legal, como los relativos a la tenencia de mascotas en caso de ruptura de un matrimonio o pareja de hecho, a los que viene aplicándoseles el régimen de los gananciales [como en la SAP de Málaga (Sección $6^{\mathrm{a}}$ ) de 12 de abril de 2012, que incluyó dos perras del matrimonio litigante en el activo de la sociedad] o, en su caso, de la comunidad de bienes (como se planteó en la SJPI de Madrid núm. 40 de 12 de marzo de 2013, en la que se discutió si un perro de la raza Jack Russel terrier y de nombre "Cachas" donado por su tía a una de las dos integrantes de una unión more uxorio, era

46 GROSSI, P./LÓPEZ LÓPEZ, A. M.: Propiedad: otras perspectivas, Fundación coloquio jurídico europeo, Madrid, 2013, p. 18.

47 Para un recorrido por los preceptos de nuestro C.c. relacionados con animales, vid. ROGEL VIDE, C.: Los animales en el Código civil, Reus, Madrid, 2017.

48 Ha de tenerse en cuenta la (extraña) salvedad realizada por el art. 346 , pfo. $2 .^{\circ}$ del C.c., que excluye de la palabra "mueble" a las caballerías (junto a carruajes y arreos) y otras cosas distintas a las enumeradas en dicho precepto "que no tengan por principal destino amueblar o alhajar las habitaciones, salvo el caso en que del contexto de la ley o de la disposición individual resulte claramente lo contrario". En ello repara CLAVERÍA GOSÁLBEZ, L. H.: Comentario al art. 346 del Código civil", en Comentario del Código civil, Tomo I, Ministerio de Justicia, Madrid, 1993, p. 949, quien considera que dicho párrafo $2 .^{\circ}$ "posee una curiosa redacción: contiene una larga lista de cosas (claramente ejemplificadora, no exhaustiva) que no se reputan comprendidas en las palabras 'muebles', para, al final, terminar definiendo a dichos 'muebles' como 'cosas... que tengan por principal destino amueblar o alhajar las habitaciones', lo que (al margen de las críticas alusivas, p. ej., a la introducción de lo definido en la definición) hace innecesaria la lista antes aludida".

49 Art. 334 C.c.: "Son bienes inmuebles: 6. ${ }^{\circ}$ Los viveros de animales, palomares, colmenas, estanques de peces o criaderos análogos, cuando el propietario los haya colocado o los conserve con el propósito de mantenerlos unidos a la finca y formando parte de ella de un modo permanente".

Como señala DÍEZ PICAZO, L.: Fundamentos del Derecho civil patrimonial, Tomo III, Cívitas, Thomson Reuters, Cizur Menor (Navarra), 2008, p. 218, los requisitos de los bienes inmuebles por destino son los tres siguientes: a) el acto de destinación; b) la relación de servicio entre la cosa accesoria y la cosa principal; c) la voluntad o el propósito de quien realiza la destinación, de que el vínculo establecido en virtud de ella sea durable o permanente. 
titularidad de ambas o sólo de la donataria del animal), lo que nos devuelve nuevamente a la cosificación de los animales.

Respecto al creciente aumento de tales casos en los últimos tiempos se pronuncia la SAP de León (Sección 1. ${ }^{\mathrm{a}}$ ) de 25 de noviembre de 2011:

"No resulta extraño que en convenios reguladores de la separación, el divorcio y sus efectos, se contemplen disposiciones para regular la posesión de las mascotas porque es evidente el cariño y afecto que surge por estos animales entre quienes les han cuidado, estableciendo en ocasiones derechos de utilización alterna y otras medidas que favorecen el cuidado por ambos propietarios" (FJ.2. $\left.{ }^{\circ}\right)$.

En el caso enjuiciado se plantea una situación de enorme interés y en la que no existe, a día de hoy, unanimidad en nuestros tribunales: si cabe un efectivo derecho de visitas a un animal similar al de los hijos comunes (sí contemplado éste pero no aquél en el art. 103 C.c.) y si las controversias relativas al mismo son susceptibles de ser enjuiciadas en el proceso de familia en el ámbito obligacional de las medidas reguladoras de la crisis familiar y, en definitiva, si posteriormente podría solicitarse la ejecución de las mismas dentro de dicho proceso. En ambas instancias se consideró inapropiada la adopción de la medida relativa a la tenencia del perro en un proceso de ruptura matrimonial y, por consiguiente, no fue aprobada.

Repárese también que nuestro Código civil, en sede de responsabilidad civil extracontractual, únicamente contempla al animal como agente del daño, jamás como víctima. Ello está en sintonía con la consideración de los animales como cosas que reportan ventajas a su titular y por cuyas acciones dañosas, como las de las máquinas (tal y como los consideraba René Descartes en su famoso Discurs de la mètode, "machine animate") aquél debe responder. De todos modos, creemos que el perjuicio ocasionado por un tercero a un animal encuentra justificación en el principio alterum non laedere ${ }^{51}$, aplicado hasta ahora exclusivamente a personas pero nada impide que se aplique a todos los seres vivos sintientes, humanos y no humanos.

Pues bien, para remediar el anacronismo que caracteriza a nuestra legislación civil, treinta años después del Convenio europeo sobre protección de animales de compañía, en concreto, el 13 de octubre de 2017, el grupo parlamentario popular presentó una proposición de ley de modificación del Código Civil, la Ley Hipotecaria y la Ley de Enjuiciamiento Civil, sobre el régimen jurídico de los animales ${ }^{52}$, la cual fue aprobada por unanimidad en el Congreso de los Diputados el 13 de diciembre de 2017 pero su tramitación se vio paralizada por el fin de la legislatura y la disolución de las Cortes generales ${ }^{53}$, sin que aún, por causa de los últimos vaivenes políticos, haya podido ser retomada.

50 Altamente recomendable es la novela La insoportable levedad del ser (1984) del escritor checo Milan Kundera, quien refleja las posiciones contrapuestas mantenidas por Descartes y Nietzsche hacia los animales.

51 Dicha máxima fue enunciada por Ulpiano (Digesto $1,1,10$ ) y ha sobrevivido hasta nuestros días.

52 Puede consultarse en http://www.congreso.es/public_oficiales/L12/CONG/BOCG/B/BOCG-12-B-167-1.PDF\#page=1.

53 Las enmiendas al articulado pueden consultarse en http://www.congreso.es/public_oficiales/L12/CONG/BOCG/B/ BOCG-12-B-167-4.PDF y el Informe de la Ponencia de 1 de marzo de 2019 en http://www.congreso.es/public oficiales/L12/CONG/BOCG/B/BOCG-12-B-167-5.PDF. 
Dicha iniciativa legislativa considera a los animales "seres vivos dotados de sensibilidad", como puede apreciarse en su Exposición de motivos ${ }^{54}$ y en la nueva redacción propuesta para algunos preceptos de los textos legales que pretende reformar ${ }^{55}$.

Pese a que, lamentablemente, no ha podido transformarse en norma, dicha proposición de ley está siendo tenida en cuenta por nuestros jueces y tribunales, como en la reciente Sentencia del Juzgado de Primera Instancia núm. 9 de Valladolid de 27 de mayo de 2019 y a citada antes, acerca de un perro de raza west highland terrier, adquirido conjuntamente por una pareja pero figurando sólo uno de ellos como titular administrativo en el microchip. Tras la ruptura sentimental, surge la controversia de la titularidad del can y de su posesión compartida ${ }^{56}$, situación ésta de la que, cada vez más, están conociendo nuestros órganos judiciales, como hemos apuntado hace un momento. Si bien en un primer momento la pareja acordó una tenencia compartida del animal y el abono del $50 \%$ de sus gastos, se acudió a la vía judicial al alegar uno de ellos que el can era suyo al estar registrado a su nombre y al haber sido comprado por él. El Juzgado se hace eco de la mentada proposición de ley, hace un apunte de Derecho comparado y, con base en el art. 3 del C.c. que establece que las normas se interpretarán "según la realidad social del tiempo en que han de ser aplicadas", así como en el art. 13 del TFUE, considera al perro como un sujeto dotado de especial sensibilidad, razón por la cual otorga a ambos propietarios un derecho de posesión y disfrute compartido del animal de compañía.

En el Derecho foral, el art. 511-1.3 del Código civil de Cataluña se alinea con los países que optan por la fórmula de animal-no cosa al disponer: "los animales, que no se consideran cosas, están bajo la protección especial de las leyes. Solo se les aplican las reglas de los bienes en lo que permite su naturaleza".

Como sucede con otros Códigos civiles ya mencionados con anterioridad, la redacción del precepto catalán podría afirmarse que tiene un alcance meramente simbólico puesto que, aunque considera que los animales no son cosas, el régimen jurídico de los bienes sigue siéndoles de aplicación. Pese a ello, nuestra valoración es muy positiva por-

54 Como afirma en su Exponendo I, "la actual regulación de los bienes del Código Civil dota a los animales del estatuto jurídico de cosas, en concreto con la condición de bienes muebles. Resulta paradójico que el Código Penal ya distinguiera en 2003, entre los daños a los animales domésticos y a las cosas, reforma sobre la que se profundizó en 2015, mientras que el Código Civil sigue ignorando que los animales son seres vivos dotados de sensibilidad. La reforma del régimen jurídico de los animales en el Código Civil español sigue las líneas que marcan otros ordenamientos jurídicos próximos, que han modificado sus Códigos Civiles para adaptarlos a la mayor sensibilidad social hacia los animales existente en nuestros días, y también para reconocer su cualidad de seres vivos y sintientes". Y continúa en el siguiente: "la reforma afecta, en primer lugar, al Código Civil, con vistas a sentar el importante principio de que la naturaleza de los animales es distinta de la naturaleza de las cosas o bienes, principio que ha de presidir la interpretación de todo el ordenamiento. De esta forma, junto a la afirmación del actual artículo 333, según el cual 'todas las cosas que son o pueden ser objeto de apropiación se consideran como bienes muebles o inmuebles', se concreta que los animales no son cosas, sino seres dotados de sensibilidad, lo que no implica que en determinados aspectos no se aplique supletoriamente el régimen jurídico de las cosas. Pasan así los animales a estar sometidos solo parcialmente al régimen jurídico de los bienes o cosas, en la medida en que no existan normas destinadas especialmente a regular las relaciones jurídicas en las que puedan estar implicados animales, y siempre que dicho régimen jurídico de los bienes sea compatible con su naturaleza de ser vivo dotado de sensibilidad y con el conjunto de disposiciones destinadas a su protección".

55 Para un análisis de dicha iniciativa legislativa, vid. ARRIBAS ATIENZA, P.: "El nuevo tratamiento civil de los animales", en Diario La Ley, Núm. 9136, Sección Tribuna, 9 de febrero de 2018 (LA LEY 872/2018).

56 Repárese en que en estos casos la terminología que utilizan nuestros órganos judiciales es la "posesión o tenencia compartida" y no la de "custodia compartida", reservada exclusivamente a los hijos menores de edad en los procesos de familia. 
que permite a los jueces realizar una exégesis actual y dinámica de las normas bajo la consideración de que un animal no es una cosa y, al mismo tiempo, reviste un importante valor pedagógico que va permeando paulatinamente en la sociedad, lo que no es poco.

En definitiva, es necesario redefinir el estatuto jurídico-civil (entiéndase por tal no sólo el Código sino también otras normas a él conexas como la Ley hipotecaria y la Ley de Enjuiciamiento civil) de los animales en nuestro ordenamiento desterrando completamente la vieja concepción de su cosificación. Los animales no pueden seguir rigiéndose por los principios y reglas concernientes a las cosas. No estamos al día ni con los avances, ni con el sentir de la ciudadanía que impera en la actualidad, ni con el Derecho civil europeo, ni tampoco con las restantes ramas de nuestro ordenamiento jurídico. Por todo ello, debemos afrontar una reforma y, además, pronto $^{57}$.

Mientras tanto, los aplicadores del Derecho seguirán rigiéndose por el Derecho actual, como deja muy claro la SAP de Guipúzcoa (Sección 2. a) de 17 de junio de 2013 sobre la apropiación indebida de un perro de raza boarder collie perdido y que en su FJ. 2. ${ }^{\circ}$ señala:

"Y con independencia de los loables deseos de las recurrentes de conseguir desde el punto de vista de su calificación jurídica, un trato y consideración de los animales más allá del de simples bienes muebles, lo cierto es que mientras tal posibilidad no se refleje en las leyes, dicho seres quedan bajo la órbita de los bienes susceptibles de apropiación".

\subsection{La jungla administrativa}

Es la labor desarrollada en el ámbito del Derecho administrativo en los últimos veinte años la que ha logrado que nuestro ordenamiento se ocupe (y preocupe) de la protección y bienestar del animal.

A nivel estatal contamos con algunas regulaciones de distinto rango relativas a los animales ${ }^{58}$, si bien la mayoría son normas sectoriales fruto de la transposición de Directi-

57 Según REY PÉREZ, J. L.: Los derechos de los animales en serio, cit., p. 17, "la voluntad homogeneizadora burguesa de un Derecho civil del siglo XIX que se ha quedado arcaico en su concepción de la persona, de la capacidad, de la propiedad, de las sucesiones y (pese a las reformas) de la familia, hace que esta rama sea las más reticente a los avances filosóficos y sociológicos que en la consideración moral de los animales se han producido en las últimas décadas. Quizá la gran reforma jurídica pendiente sea la del Derecho civil, pero en tanto esta no se produzca tendremos que lidiar con sus concepciones aunque se hayan quedado ancladas en un pasado muy remoto".

58 De entre las normas de fecha más antigua, podemos citar la Real Orden Circular de 26 de diciembre de 1925, que estableció con carácter obligatorio la protección de los animales y las plantas y declaró de utilidad pública las asociaciones que tuvieran por fin divulgar y arraigar dicha protección; la Real Orden de 1 de julio de 1927, por la que se estableció la obligación de recoger a aquellos perros que, vagabundos, circularan por la ciudad, con el fin de evitar posibles riesgos sanitarios; el Real decreto de 11 de abril de 1928, por el que se aprobó el Reglamento de los patronatos para la protección de animales y plantas.

Entre las normas preconstitucionales aún en vigor se encuentran el Decreto de 17 de mayo de 1952 por el que se declara obligatorio el registro y matrícula de los perros y la vacunación a los mismos por cuenta de sus dueños, la Orden de 5 de diciembre de 1974 por la que se dictan normas complementarias al artículo 3. ${ }^{\circ}$ del Decreto de 17 de mayo de 1952 respecto a la recogida de perros vagabundos y el Decreto 1119/1975, de 24 de abril, sobre autorización y registro de núcleos zoológicos, establecimientos para la práctica de la equitación, centros para el fomento y cuidado de animales de compañía y similares.

Para un recorrido histórico por la normativa española en relación a la protección y bienestar de los animales vid. PEREZ MONGUIÓ, J. M.a: "Marco jurídico de la protección animal en España desde 1929 hasta 2015: el lento y firme trote del mastín", cit. (BIB 2015\17053). 
vas europeas ${ }^{59}$. En este sentido se pronuncia el Auto del Juzgado de Instrucción de Lugo de 14 de noviembre de 2017:

“en España, como en tantas otras materias, (protección de los consumidores, por poner un ejemplo) la evolución de la normativa estatal ha venido de la mano del Derecho derivado comunitario, dictándose una serie de normas administrativas y sectoriales para dar cumplimiento a las obligaciones asumidas en este ámbito a nivel europeo (normas en materia de sacrificio y matanza, protección de los animales utilizados para experimentación y otros fines científicos y regulación de las condiciones de vida de los animales en explotaciones ganaderas)" (FJ. 1..$^{\circ}$.

Sin embargo, han sido las CCAA las que, en el marco de la distribución de competencias ex arts. 148 y 149 de la CE, han afrontado la regulación del bienestar y tenencia responsable de los animales. De este modo, la intervención pública en este ámbito ha sido regulada autonómicamente y ante el completo olvido de la protección animal por parte de nuestra Carta Magna, ello se ha hecho con base en varios títulos competenciales como, entre otros, sanidad e higiene, ganadería, cultura, ocio y espectáculos, protección del medio ambiente y la fauna o seguridad pública.

Como señala el Auto lucense apenas citado,

"al no proclamarse un derecho constitucional del bienestar animal, no es de extrañar que la Constitución tampoco contenga título competencial habilitante de las competencias en materia de protección y bienestar animal, no resultando claro, a tenor del sistema de distribución competencial que efectúan los arts. 148 y 149 de la $\mathrm{CE}$, quién debe asumir las competencias en estas materias, lo que determinó que en la práctica ni el Estado ni los primeros Estatutos de Autonomía legislaran ni contuvieran la más mínima alusión al respecto salvo tras las reformas posteriores de tales estatutos en el caso de Cataluña y Andalucía, que terminaron acogiendo una competencia expresa sobre protección de los animales" (FJ. 1. ${ }^{\circ}$ ).

Así las cosas, nos encontramos con diecisiete leyes autonómicas, tantas como CCAA existen en nuestro país ${ }^{60}$ (y los respectivos reglamentos de las Ciudades Autónomas de Ceu-

59 Entre otras, la Ley 50/1999, de 23 de diciembre, sobre régimen jurídico de la tenencia de animales potencialmente peligrosos junto con el RD 287/2002, de 22 de marzo, que la desarrolla; el RD 348/2000, de 10 de marzo, por el que se incorpora al ordenamiento jurídico la Directiva $98 / 58 / \mathrm{CE}$, relativa a la protección de los animales en las explotaciones ganaderas; la Ley 8/2003, de 24 de abril, de sanidad animal; la Ley 31/2003, de 27 de octubre, de conservación de la fauna silvestre en los parques zoológicos, de transposición de la Directiva 1999/22/CE del Consejo, de 29 de marzo de 1999, relativa al mantenimiento de animales salvajes en parques zoológicos; la Ley 32/2007, de 7 de noviembre, para el cuidado de los animales en su explotación, transporte, experimentación y sacrificio (la cual, por cierto, no se aplica, con algunas salvedades, a los animales de compañía ex art. 2.2. d) y el RD 37/2014, de 24 de enero, que la desarrolla; el RD 53/2013, de 1 de febrero, por el que se establecen las normas básicas aplicables para la protección de los animales utilizados en experimentación y otros fines científicos; y el RD 542/2016, de 25 de noviembre, sobre normas de sanidad y protección animal durante el transporte.

60 Siguiendo un orden alfabético de las CCAA, sus respectivas legislaciones son: Ley 11/2003, de 24 de noviembre, de protección de los animales, de la Comunidad autónoma de Andalucía; Ley 11/2003, de 19 de marzo, de protección Animal en la Comunidad autónoma de Aragón; Ley 13/2002, de 23 de diciembre, de tenencia, protección y derechos de los animales del Principado de Asturias; Ley 1/1992, de 8 de abril, de protección de los Animales que viven en el entorno humano de la Comunidad autónoma de islas Baleares; Ley 8/1991, de 30 de abril, de protección de los animales de la Comunidad autónoma de islas Canarias; Ley 3/1992, de 18 de marzo, de protección de los animales de la Comunidad autónoma de Cantabria; Ley 7/1990, de 28 de diciembre, de protección de los animales domésticos de la Comunidad autónoma de Castilla-La Mancha; Ley 5/1997, de 24 de abril, de protección de los animales de compañía de la Comunidad autónoma de Castilla y León; Decreto Legislativo 2/2008, de 15 de abril, por el que se aprueba el Texto refundido de la Ley de protección de los animales de la Comunidad autónoma de 
ta y Melilla ${ }^{61}$ ), publicadas en momentos distintos y no todas igual de garantistas del bienestar animal, sin que, a día de hoy, exista una norma marco estatal que las armonice mediante el establecimiento de unos estándares mínimos, tal y como sería deseable.

Cierto es que todas tienen en común regular los distintos aspectos de la convivencia humana-animal ${ }^{62}$, por ello que suelan coincidir en la imposición de unas obligaciones básicas como son la identificación y registro del animal, el ejercicio de su tenencia responsable o la presencia de animales en espacios públicos. Sin embargo, existe una gran heterogeneidad entre ellas. Por de pronto, ni siquiera el objeto es el mismo en todas ellas, pues algunas de las leyes autonómicas se limitan a los animales de compañía, mientras que otras son mucho más ambiciosas y comprenden también los domésticos y los silvestres en cautividad.

La falta de uniformidad normativa y sus consiguientes disfunciones crea una enorme inseguridad jurídica hasta el punto de que el animal que obligatoriamente ha de ser registrado en una Comunidad autónoma no tiene por qué serlo en otra, lo que está prohibido en una región no lo está en otra o bien, estando vetado en dos, la sanción por incumplimiento difiere considerablemente entre ellas ${ }^{63}$, y en unas se contempla como medida accesoria junto a la sanción económica por una infracción la inhabilitación para la tenencia o adquisición de animales durante un periodo de tiempo y en otras no. En suma, da la impresión de que la sensibilidad hacia los animales por parte de los españoles varía en función del territorio, lo que es inconcebible.

Este desigual panorama normativo consecuencia de la plural acción legislativa autonómica es puesto de manifiesto por el mencionado Auto del Juzgado lucense:

“con todo, ante la gran asignatura pendiente de poder disponer en algún momento de la ansiada ley estatal de protección animal, han sido las Comunidades Autónomas las que han ido avanzando progresivamente en la tutela administrativa de los animales domésticos (incluidos los de compañía), dictando leyes, en cuyos preámbulos se consagra la creciente preocupación por el bienestar de los animales y se les protege frente a las situa-

Cataluña, que deroga la Ley 3/1988, de 4 de marzo, de protección de los animales, primera normativa autonómica en regular la materia; Ley 4/1994, de 8 de julio, de la Generalidad Valenciana, sobre protección de los animales de compañía; Ley 5/2002, de 23 de mayo, de protección de los animales en la Comunidad autónoma de Extremadura; Ley 4/2017, de 3 de octubre, de protección y bienestar de los animales de compañía en Galicia; Ley 4/2016, de 22 de julio, de protección de los animales de compañía de la Comunidad de Madrid; Ley 6/2017, de 8 de noviembre, de protección y defensa de los animales de compañía de la Región de Murcia; Ley Foral 19/2019, de 4 de abril, de protección de los animales de compañía en Navarra, que sustituye a la Ley Foral 7/1994, de 31 de mayo, de protección de los animales; Ley 6/1993, de 29 de octubre, de protección de los animales de la Comunidad autónoma del País Vasco y Ley 6/2018, de 26 de noviembre, de protección de los animales en la Comunidad autónoma de La Rioja.

61 Por lo que respecta a las Ciudades autónomas de Ceuta y Melilla, al no tener Parlamento no tienen leyes sino reglamentos, de manera que en la primera rige el Reglamento 2/2015 de 23 de marzo, de tenencia, protección y bienestar de animales de compañía y en la segunda existe únicamente la Ordenanza reguladora de la Sanidad animal de 1997.

62 Como señala PEREZ MONGUIÓ, J. M. a: "El concepto de animal de compañía: un necesario replanteamiento”, en Revista Aragonesa en Administración Pública, 2018, núm. 51, p. 247, "todas las leyes autonómicas de protección animal, con distintos alcances, tienen en común el propósito de alcanzar una regulación comprensiva de aquellos aspectos que pueden afectar a la convivencia del hombre con los animales que desempeñan esta función y la relación de estos últimos con el resto de la sociedad, junto con unos principios proteccionistas en su acepción de bienestar que inspiran todo lo normativo".

63 Como botón de muestra, la sanción para las infracciones graves en la Ley andaluza 11/2003 es de 2001 a 30000 euros mientras que en la más reciente Ley navarra 19/2019 la multa es de 6001 a 100000 euros. 
ciones de maltrato de la que a menudo son objeto, estableciendo como uno de sus fines el de asegurar 'una eficaz protección de los animales en sí mismos, evitándoseles los tratos degradantes, crueles o simplemente abusivos, por parte del hombre' (Exposición de motivos de la Ley 5/1997, de la Comunidad autónoma de Castilla y León, de 24 de abril, de protección de los animales de compañía).

A cambio, el precio que ha de pagarse es el de la disparidad de regímenes jurídicos, hasta el punto de que existen legislaciones muy avanzadas, como es el caso de la Comunidad autónoma de Cataluña, que ha sido pionera en materia de protección animal y otras, en las que los animales no resultan tan afortunados, con las esquizofrénicas consecuencias de que un perro en una Comunidad autónoma es peligroso y en otra no y que lo que está prohibido en una Comunidad autónoma está permitido en otra, generando una grave inseguridad jurídica" (FJ. 1. ${ }^{\circ}$ ).

Pero ahí no queda la cosa, pues, además de las diecisiete diferentes maneras de legislar la materia, ha de tenerse en cuenta el gran protagonismo que las Administraciones locales ostentan en este ámbito.

Además de las competencias delegadas por la legislación sectorial, la Ley 7/1985, de 2 de abril, Reguladora de las Bases del Régimen Local, si bien no atribuye expresamente competencias en materia de protección de animales, contiene en sus arts. 25 y 26 títulos competenciales que, indirectamente, habilitan a los municipios a regular aspectos relativos a la tenencia de animales con ocasión de su intervención normativa en medio ambiente urbano, salubridad pública, servicios de limpieza viaria o de recogida de residuos. Sobre esta base competencial, los Ayuntamientos dictan Ordenanzas municipales de tenencia y protección animal ${ }^{64}$, las cuales difieren también las unas de las otras, por ejemplo, a la hora de regular el número y tipología de animales de compañía permitidos en un inmueble ${ }^{65}$. Por consiguiente, para la tenencia de mascotas habrá de estarse a la normativa correspondiente al lugar (tanto región como municipio) de residencia habitual.

A la vista de la dispersión y diversidad normativa en la materia (una auténtica jungla, si se nos permite la expresión a tono con la temática objeto de análisis), consideramos necesaria y urgente una ley estatal de armonización que unifique conceptos, obligaciones,

64 Según el Auto del Juzgado de Instrucción de Lugo de 14 de noviembre de 2017, a la disparidad de las normas autonómicas "ha de añadirse que pese al vacío legal de la Ley 7/1985, de 2 de abril, Reguladora de las Bases del Régimen Local, en cuyos artículos 25 y 26 no se atribuye expresa ni específicamente competencias ni servicios a los Municipios sobre esta materia, los Ayuntamientos, amparados en las competencias del artículo 25 en materia de medio ambiente, protección de la salubridad pública y seguridad, entre otras, han pasado a regular los aspectos relativos a la protección de los animales, cuyas funciones sí que han sido cedidas por las leyes de protección autonómicas dictando diversas ordenanzas municipales sobre tenencia de animales, infracciones y sanciones" (FJ. . $^{\circ}$ ).

65 Para que el lector pueda hacerse una idea, el art. 16 de la Ordenanza municipal de animales de compañía del Ayuntamiento de Salamanca de 1999 en viviendas urbanas permite la tenencia como, máximo de tres perros o tres gatos adultos o diez aves (salvo que se autorice por licencia municipal un número superior), el art. 4 de la Ordenanza municipal reguladora de la tenencia y protección de los animales del Ayuntamiento de Madrid de 2001 establece que el número de gatos y perros que pueden tenerse como máximo en un domicilio particular es de cinco, idéntico número fijado por el art. 9 de la Ordenanza municipal de tenencia de animales de compañía y animales potencialmente peligrosos del Ayuntamiento de Almería de 2017, número que reduce a tres perros el art. 9.b) de la Ordenanza municipal reguladora de la tenencia de animales del Ayuntamiento de Granada de 2014 salvo que la vivienda particular "reúna las condiciones necesarias para albergarlos según se exponga en informe motivado que a tal fin emitirán de oficio, a petición de parte o denuncia, los Servicios Veterinarios Municipales". 
infracciones y sanciones, proporcionando los principios fundamentales para alcanzar el mismo nivel de protección y bienestar para los animales en todo el territorio español.

\subsection{La insatisfactoria tutela penal}

Junto al Derecho administrativo, el otro pilar absolutamente decisivo en la protección y bienestar animal es, sin duda alguna, el Derecho penal.

Compartimos plenamente lo expresado por el tan ya citado Auto del Juzgado de Instrucción núm. 1 de Lugo de 14 de noviembre de 2017, que conoció del caso de una perra que cayó al vacío desde la ventana de un piso y cuyos propietarios se negaron a que recibiera posterior tratamiento veterinario:

"la dignidad de los animales como política pública es muy reciente en la historia del Derecho pero los poderes públicos no pueden delegar su ámbito de actuación a las sociedades protectoras o animalistas, por recién estrenado que esté el denominado Derecho Animal, sino que, por el contrario, están obligados a una mayor intervención para la tutela de los animales desplegando todo su potencial, legal, policial y judicial con el fin de lograr su completa efectividad, y en todos los planos, tanto el de la prevención, con políticas educativas como el de la represión y sanción".

Y continúa afirmando en su FJ. 1. :

"contamos con una dispersa normativa administrativa, cuyo fracaso junto con el de las políticas de prevención, reeducación y concienciación social ha determinado la necesidad de reforzar la protección punitiva a través de la tipificación del delito de maltrato animal".

Los países europeos sancionaban desde hace tiempo los comportamientos crueles con animales, si bien lo hacían exigiendo que aquéllos tuvieran lugar en público, requisito ya eliminado en los Códigos penales actuales ${ }^{66}$.

El nuestro, tras la reforma operada por la Ley Orgánica 1/2015, de 30 de marzo, tipifica el delito de maltrato animal (art. 33767) y el de abandono animal

66 Art. 727 del CP italiano, art. 222 del StGB austríaco, art. 13 del CP sueco y art. 17 del CP alemán.

67 El maltrato animal no fue contemplado como delito (con anterioridad era considerado como falta en el art. 632 del CP) hasta la Ley Orgánica 15/2003, de 25 de noviembre, la cual tipificó como falta en el art. 631.2 el abandono de un animal doméstico.

Con posterioridad, el art. 337 CP recibió sendas redacciones por las Leyes Orgánicas 5/2010, de 22 de junio y 1/2015, de 30 de marzo, el cual, en la actualidad, tiene el siguiente tenor literal: "1. Será castigado con la pena de tres meses y un día a un año de prisión e inhabilitación especial de un año y un día a tres años para el ejercicio de profesión, oficio o comercio que tenga relación con los animales y para la tenencia de animales, el que por cualquier medio o procedimiento maltrate injustificadamente, causándole lesiones que menoscaben gravemente su salud o sometiéndole a explotación sexual, a

a) un animal doméstico o amansado,

b) un animal de los que habitualmente están domesticados,

c) un animal que temporal o permanentemente vive bajo control humano, o

d) cualquier animal que no viva en estado salvaje.

2. Las penas previstas en el apartado anterior se impondrán en su mitad superior cuando concurra alguna de las circunstancias siguientes:

a) Se hubieran utilizado armas, instrumentos, objetos, medios, métodos o formas concretamente peligrosas para la vida del animal.

b) Hubiera mediado ensañamiento.

c) Se hubiera causado al animal la pérdida o la inutilidad de un sentido, órgano o miembro principal.

d) Los hechos se hubieran ejecutado en presencia de un menor de edad. 
(art. 337 bis $^{68}$ ), los cuales tienen como bien jurídico protegido los derechos de los animales $^{69}$.

Desde entonces, han aumentado el número de denuncias por este tipo de hechos ${ }^{70}$, se han iniciado multitud de procedimientos penales, se han dictado algunas sentencias condenatorias $^{71}$ y en poquísimas ocasiones se ha cumplido la pena privativa de libertad impuesta $^{72}$.

Lo cierto es que, en la práctica, la aplicación del Derecho animal sancionador no está siendo en España todo lo efectiva que debiera ${ }^{73}$ y, si acaso, las sanciones admi-

3. Si se hubiera causado la muerte del animal se impondrá una pena de seis a dieciocho meses de prisión e inhabilitación especial de dos a cuatro años para el ejercicio de profesión, oficio o comercio que tenga relación con los animales y para la tenencia de animales.

4. Los que, fuera de los supuestos a que se refieren los apartados anteriores de este artículo, maltrataren cruelmente a los animales domésticos o a cualesquiera otros en espectáculos no autorizados legalmente, serán castigados con una pena de multa de uno a seis meses. Asimismo, el juez podrá imponer la pena de inhabilitación especial de tres meses a un año para el ejercicio de profesión, oficio o comercio que tenga relación con los animales y para la tenencia de animales".

Para un detenido estudio de la materia, vid. REQUEJO CONDE, C.: "El delito de maltrato a los animales tras la reforma del Código penal por la Ley Orgánica 1/2015, de 30 de marzo”, en dA: Derecho animal, vol. 6, núm. 2 , 2015, pp. 1-26.

68 El art. 337 bis, introducido por la Ley Orgánica 1/2015, dispone: "El que abandone a un animal de los mencionados en el apartado 1 del artículo anterior en condiciones en que pueda peligrar su vida o integridad será castigado con una pena de multa de uno a seis meses. Asimismo, el juez podrá imponer la pena de inhabilitación especial de tres meses a un año para el ejercicio de profesión, oficio o comercio que tenga relación con los animales y para la tenencia de animales".

69 Acerca de la polémica doctrinal acerca de cuál es el bien jurídico protegido en el delito de maltrato a los animales, vid. VERCHER NOGUERA, A.: "Nuevas perspectivas sobre el bien jurídico protegido en los delitos ambientales: ¿cabría hablar de derechos no humanos de los animales domésticos frente a su maltrato?, en Diario La Ley, Núm. 8994, Sección Doctrina, 6 de Junio de 2017 (LEY 5744/2017).

Al respecto, el Auto del Juzgado de Instrucción núm. 1 de Lugo de 14 de noviembre de 2017 considera zanjada dicha polémica al afirmar que la tipificación del delito de maltrato animal "ha de llevar al fin de la eterna discusión acerca de cuál sea el bien jurídico tutelado, que no es otro que el bienestar animal o dicho de otra forma, el derecho del animal a gozar de vida, salud, integridad física y psíquica y la ausencia de sufrimientos innecesarios" (FJ. $1 .^{\circ}$ ).

70 En 2018 el Servicio de Protección de la Naturaleza (SEPRONA) de la Guardia Civil detuvo o investigó a 590 personas por delitos de maltrato animal, año en el que se cursaron 16625 denuncias (10920 relacionadas con animales de compañía, 3974 con animales peligrosos y 1731 con razas caninas peligrosas).

71 Según la Memoria de la Fiscalía General del Estado del año 2018 (https://www.fiscal.es/fiscal/PA_WebApp_ SGNTJ NFIS/descarga/MEMFIS18.PDF ?idFile=f9e5ea88-f1f6-4d21-9c24-d2ffd93eabc3), en el año 2017 de dictaron 163 sentencias condenatorias por malos tratos a animales domésticos.

Destacamos, por su ejemplaridad, el citado Auto del Juzgado de Instrucción núm. 1 de Lugo de 14 de noviembre de 2017 en el que se decreta una orden de alejamiento a los propietarios de una perra (la distancia mínima a la que pueden acercarse son 500 metros) a la que aquéllos habían arrojado al vacío desde un piso.

72 Como en el caso del caballo de carreras "Sorky das Pont", el caso del perro "Mix" o, más recientemente, el de la perra Milagros (a la que la Magistrada llamó como testigo con el fin de concienciar a la sociedad sobre el maltrato animal), en los que, ante la gravedad de los hechos, no se procedió a la sustitución ni a la suspensión de la ejecución de las penas privativas de libertad por delitos de maltrato animal con el consiguiente ingreso en prisión de los maltratadores.

73 De esta opinión MENÉNDEZ DE LLANO RODRÍGUEZ, N.: "Evolución de la sanción penal por maltrato animal: el caso español”, en Diario La Ley, Núm. 9038, Sección Tribuna, 11 de septiembre de 2017 (LA LEY 10969/2017), para quien "ello puede deberse a diversos factores como la falta de formación específica en Derecho Animal, la falta de sensibilidad entre los operadores jurídicos, que no siempre perciben los casos de maltrato animal como graves, o la falta de protocolos legales que determinen de oficio, por ejemplo, el decomiso del animal, el examen veterinario-forense del animal víctima del supuesto maltrato o el nombramiento de un depositario judicial para que se haga cargo de su custodia, etc.”. Y añade a continuación: “también es esencial que las leyes, sobre todo aquellas que pretenden modificar prejuicios y formas de violencia tan arraigados en determinados contextos sociales, vayan acompañadas de recursos que permitan instaurar políticas públicas efectivas que trabajen acompasadamente en distintos planos como el preventivo, el educativo, o el formativo". 
nistrativas se muestran algo más eficaces en cuanto al fin disuasorio perseguido que las penales.

Sin desmerecer los grandes pasos dados por el legislador, es evidente que la regulación penal actual no satisface adecuadamente las necesidades de la sociedad ${ }^{74}$. Es claro que en dicho ámbito es imprescindible acometer mejoras que permitan un mayor grado de protección, clarifiquen términos legales que son equívocos para los aplicadores del Derecho (como el "injustificadamente" del art. $337^{75}$ ), endurezcan las penas ${ }^{76}$ y solucionen deficiencias como la falta de tipificación del maltrato a los animales que viven en estado salvaje ${ }^{77}$, evidente ausencia que tiene como fin último justificar actividades como la caza. Y todo ello, tal vez, deba ser recogido en un capítulo específicamente destinado a la tipificación de los delitos de maltrato animal, dentro del Título XVI del Código penal. Conscientes de las deficiencias del actual reproche penal del maltrato y abandono animal, el Grupo Parlamentario Confederal de Unidos Podemos-En Comú Podem-En Marea presentó la proposición de Ley de modificación del Código Penal en materia de maltrato animal, publicada en el Boletín Oficial de las Cortes Generales el 2 de febrero de $2018^{78}$.

De todos modos, insistimos, junto a una adecuada respuesta punitiva es esencial una intervención de concienciación y educación de la ciudadanía que fomente, de manera preventiva, una conducta cívica y una tenencia responsable de los animales.

Hacia ello apunta, con gran acierto, el citado Auto del Juzgado de Instrucción núm. 1 de Lugo de 14 de noviembre de 2017, en su FJ 1. ${ }^{\circ}$, el cual se muestra bastante crítico con nuestro sistema legal, administrativo y policial:

"el creciente rechazo ciudadano al maltrato animal que ha ido calando con fuerza en la conciencia ciudadana, no se ve respaldado por un sistema legal que resulte operativo, como revelan los datos oficiales, con arreglo a los cuales son muy escasas todavía las sentencias condenatorias a pesar de la duplicación de las denuncias por maltrato animal, lo que puede explicarse por múltiples factores, que van desde la falta de formación y sensibilidad entre los operadores policiales y jurídicos, a la falta de formación en Derecho animal, o la no inversión en recursos educativos y económicos que permitan establecer

74 De esta opinión, DE ROJAS MARTÍNEZ-PARETS, F.: "La protección de los animales domésticos y en cautividad en las normativas autonómicas", en Revista Aranzadi de Derecho Ambiental, 2005, núm. 8 (BIB 2005\1477): "está claro sin embargo que la represión penal resulta, a todas luces, insuficiente. El Código Penal requiere actualmente de la concurrencia de unas circunstancias que habrían de ser excepcionales como son el ensañamiento y la total falta de justificación en la muerte y lesión grave de un animal. Pero es que, además, la solución no puede reposar mayormente en la represión penal, que se ha de guardar para aquellos casos más reprobables".

75 El Auto del Juzgado de Instrucción núm. 1 de Lugo de 14 de noviembre de 2017 crítica la utilización de dicho término: "no podemos dejar de mencionar el inquietante y distorsionador elemento que ha supuesto la inclusión en el tipo penal del término 'injustificadamente', ya que ningún maltrato resulta justificado y con cuyo empleo parece quererse excluir del tipo a aquellos supuestos que si bien serían susceptibles de ser calificados como de maltrato a animales, son socialmente aceptados, cuando se desarrollen en determinadas condiciones establecidas legalmente (por ejemplo, la experimentación con animales) o bien cuando se alegue la legítima defensa, o cuando la justificación resida en proteger un bien que se entiende de valor superior, como la seguridad ciudadana. El problema es que la utilización de un concepto en blanco y tan abierto como el de 'injustificado' puede suponer el dejar una vía abierta para la punición o no, que dependerá de la mayor o menor sensibilidad del fiscal o del juzgador" (FJ. 1. ${ }^{\circ}$ ).

76 De "bastante liviana" califica el Auto lucense de 14 de noviembre de 2017 la pena del delito de maltrato animal.

77 Dicho vacío legal ha sido puesto de manifiesto recientemente por el Juzgado de Primera Instancia e Instrucción número 3 de Huesca en su Auto de 11 de marzo de 2019, en relación al maltrato y tortura a un zorro por un cazador en un coto de caza, que apunta que el sujeto pasivo de tales tipos penales deben ser todos los animales vertebrados sin distinción.

78 El texto puede consultarse en http://www.congreso.es/public_oficiales/L12/CONG/BOCG/B/BOCG-12-B-202-1.PDF. 
políticas de prevención y de reinserción efectivas; prueba de lo cual es lo que ha sucedido en el caso que motiva las presentes actuaciones, donde es de justicia reconocer que si este juzgado ha podido actuar a tiempo y conseguir salvar la vida de la perra y su movilidad, ha sido gracias a la actuación ciudadana y a la labor informativa desplegada en este caso, por el Diario El Progreso, que se hizo eco de las quejas vecinales, más que a la agilidad de la propia actuación administrativa ${ }^{79}$ y policial”.

\section{BIBLIOGRAFÍA}

Alonso García, E. "El bienestar de los animales como seres sensibles-sentientes: su valor como principio general, de rango constitucional, en el Derecho español", en Los principios jurídicos del Derecho administrativo, SANTAMARÍA PASTOR (dir.), La Ley, Madrid, 2010, pp. 1427-1510 (LA LEY 1120/2011).

Arribas AtienZa, P. "El nuevo tratamiento civil de los animales", en Diario La Ley, núm. 9136, Sección Tribuna, 9 de febrero de 2018 (LA LEY 872/2018).

Barzanti, F. "La tutela del benessere degli animali nel Trattato di Lisbona", en Il Diritto dell'Unione Europea, 2013, pp. 49-71.

Bécares Mendiola, C. Y González Lacabex, M. " “Avances y retos del Derecho animal en España”, en El Derecho de los animales, BALTASAR (coord.), Marcial Pons, Barcelona, 2015, pp. 245-258.

Bentham, J. Introduction to the principles of morals and legislation, printed by T. Payne and son, London, 1789 (puede consultarse en https://oll.libertyfund.org/titles/bentham-the-works-of-jeremy-bentham-vol-1/simple\#lf0872-01_head_028).

CARDozo Dias, E. A tutela jurídica dos animais, Belo Horizonte - Minas Gerais, 2018.

CARTwrigth, J. Introducción al Derecho inglés de los contratos, Aranzadi, Cizur menor (Navarra), 2019.

CAVALIERI, P. The animal question: Why non-human animals deserve human rights, Oxford University Press, New York, 2001.

Chible Villadandos, M. a J. "La protección del animal no humano a través del habeas corpus ", en Derecho y Humanidades, núm. 27, 2016, pp. 37-67.

Clavería Gosálbez, L. H. Comentario al art. 346 del Código civil”, en Comentario del Código civil, Tomo I, Ministerio de Justicia, Madrid, 1993, pp. 948-949.

De Rojas Martínez-Parets, F. "La protección de los animales domésticos y en cautividad en las normativas autonómicas", en Revista Aranzadi de Derecho Ambiental, 2005, núm. 8 (BIB 2005\1477).

Dízz Picazo, L. Fundamentos del Derecho civil Patrimonial, Tomo III, Cívitas-Thomson Reuters, Cizur Menor (Navarra), 2008.

Doménech Pascual, G. Bienestar animal contra derechos fundamentales, Atelier, Barcelona, 2004.

Francione, G. L. Animals, property and the Law, Temple University Press, Philadelphia, 1995.

Grossi, P. y López López, A. M. Propiedad: otras perspectivas, Fundación coloquio jurídico europeo, Madrid, 2013.

Lelanchon, L. "La reforma del estatuto jurídico civil de los animales en el Derecho francés", en $d A$.: Derecho Animal, 2018, vol. 9, núm. 3, pp. 72-79.

Lopez De La Osa Escribano, P. El Derecho del bienestar animal en Europa y Estados Unidos, Aranzadi, Cizur menor (Navarra), 2012.

79 BÉCARES MENDIOLA, C. y GONZÁLEZ LACABEX, M. "Avances y retos del Derecho animal en España", en El Derecho de los animales, BALTASAR (coord.), Marcial Pons, Barcelona, 2015, p. 254 señalan como uno de los grandes problemas en la defensa animal la inacción administrativa. La inactividad de la Administración como única respuesta a las denuncias de ciudadanos y entidades de protección animal constituye también una realidad con la que, desafortunadamente, se encuentran aquellos en demasiadas ocasiones, y frente a la cual el único recurso posible es el que ofrece la vía judicial". 
López De La Osa Escribano, P. "La protección jurídica de los animales en Alemania y Francia”, en Revista Aranzadi de Derecho Ambiental, 2013, núm. 25 (BIB 2013\1782).

Mazzoni, C. M. “La questione dei diritti degli animali”, en Belfagor, 2012, vol. 67, pp. 265-276.

MenÉndez De Llano RodríGuez, N. “Evolución de la sanción penal por maltrato animal: el caso español”, en Diario La Ley, núm. 9038, Sección Tribuna, 11 de septiembre de 2017 (LA LEY 10969/2017).

MüLlerová, H. "Animals finally above objects and stricter criminalization of cruelty: some insights in czech animal legislation”, en $d A$.: Derecho Animal, 2012, vol. 3, núm. 1, pp. 1-7.

Nussbaum, M. "Beyond 'Compassion and Humanity': Justice for Non-Human Animals", en Animal rights: current debates and new directions, SUNSTEIN y NUSSBAUM (eds.), University Press, Oxford, 2004.

Perez Monguió, J. M. Animales de compañía. Régimen jurídico en el Derecho administrativo, Bosch, Barcelona, 2005.

Perez Monguió, J. M. "Marco jurídico de la protección animal en España desde 1929 hasta 2015: el lento y firme trote del mastín”, en Revista Aranzadi de Derecho Ambiental, 2015, núm. 32, pp. 285-333 (BIB 2015\17053).

PÉrez Monguió, J. M. a "El concepto de animal de compañía: un necesario replanteamiento", en Revista Aragonesa en Administración Pública, 2018, núm. 51, pp. 244-280.

REgan, T. The case for animal rights, University of California Press, Los Ángeles, 1983.

Rey Pérez, J. L. Los derechos de los animales en serio, Dykinson, Madrid, 2018.

Roca Fernández-Castanys, M. ${ }^{a}$ L. El transporte intracomunitario de animales de compañia, Reus, Madrid, 2018.

Rodotà, S. Il diritto di avere diritti, Milano, Il saggiatore, 2013.

Rogel Vide, C. Los animales en el Código civil, Reus, Madrid, 2017.

Requejo Conde, C. "El delito de maltrato a los animales tras la reforma del Código penal por la Ley Orgánica 1/2015, de 30 de marzo", en $d A$ : Derecho animal, vol. 6, núm. 2, 2015, pp. 1-26.

Singer, P. Animal liberation: a new ethics for our treatment of animals, HarperCollins, Random House, New York, 1975.

VAdalÀ, V. "Prospettazione storico-evolutiva dei diritti degli animali”, en Giustizia civile, 2017, núm. 3, pp. 549-577.

Vercher Noguera, A. "Nuevas perspectivas sobre el bien jurídico protegido en los delitos ambientales: ¿cabría hablar de derechos no humanos de los animales domésticos frente a su maltrato?, en Diario La Ley, núm. 8994, Sección Doctrina, 6 de Junio de 2017 (LEY 5744/2017).

Vivas Tesón, I. Las inmisiones por tenencia de animales de compañia en inmuebles en régimen de propiedad horizontal, Aranzadi, Cizur menor (Navarra), 2019. 